\title{
Monitoring of adult emergence in the pine processionary moth between 1970 and 1984 in Mont Ventoux, France
}

\author{
Jean-Claude Martin ${ }^{\ddagger}$, Jean-Pierre Rossi§, Maurane Buradino ${ }^{\ddagger}$, Carole Kerdelhué§ \\ ‡ INRAE, UEFM, Avignon, France \\ $\S$ INRAE, CBGP, Montpellier, France
}

Corresponding author: Carole Kerdelhué (carole.kerdelhue@inrae.fr)

Academic editor: Bong-Kyu Byun

Received: 24 Nov 2020 | Accepted: 06 Feb 2021 | Published: 17 Feb 2021

Citation: Martin J-C, Rossi J-P, Buradino M, Kerdelhué C (2021) Monitoring of adult emergence in the pine processionary moth between 1970 and 1984 in Mont Ventoux, France. Biodiversity Data Journal 9: e61086. https://doi.org/10.3897/BDJ.9.e61086

\begin{abstract}
Background

The current climate change has marked impacts on the phenology of species, i.e. the timing of the various stages of their life cycle. Yet, to fully understand how phenological patterns can be modified according to changes in temperature regimes, it is of prime importance to rely on high quality historical data. Here, we propose a very valuable dataset including individual monitoring from pupation to adult emergence of 46479 individuals of pine processionary moth (Thaumetopoea pityocampa) surveyed between 1970 and 1984 in southern France along an altitudinal gradient. As optional prolonged diapause occurs in this species, i.e. some individuals experience one or more years of diapause before emerging, the caterpillars sampled in any given year were monitored during up to 5 years. The goal was to give precise information about phenology in this species to further analyse its temporal patterns of variation.
\end{abstract}




\section{New information}

This dataset is unique by its richness and the type of data it contains. Phenology in the pine processionary moth is often monitored by the use of pheromone traps in the field, which does not provide all the necessary information, because it is then not possible to trace back the exact origin of the moth trapped, nor to characterise other steps of the life cycle. Moreover, as it corresponds to historical data dating back to the 70 s and the $80 \mathrm{~s}$, the dataset provides a historical baseline of trends in the pre-warming period.

\section{Introduction}

Widely-distributed species encounter different ecological pressures throughout their range and their phenology can be locally tuned by adaptation to optimise resource use and climatic conditions faced by each life stage (Abarca and Lill 2019). In the recent years, climate change has strongly affected the phenology of many organisms, but the direction and strength of these responses proved to vary among species (Maurer et al. 2018). To analyse how species react to temperature changes, it is necessary to rely on time series that allow us to finely explore the relationship between yearly variations and the timing of major life cycle steps.

The pine processionary moth (PPM), Thaumetopoea pityocampa (Lepidoptera: Notodontidae), is a univoltine species that reproduces in summer, immediately after adult emergence. Its larvae hatch and develop throughout autumn and winter in typical white tents built in conifer branches. At the end of larval development, they leave their host tree in head-to-tail procession in search of a suitable underground pupation site, where they stay until adult emergence the following summer. A proportion of the individuals can enter a so-called prolonged pupal diapause (semi-voltine cycle). In such a case, the pupa does not emerge as an adult the following summer, but remains in diapause for one or more complete year(s) and emerges one or several years after the other individuals (Battisti et al. 2015). The timing of adult emergence and sexual reproduction is dependent on local environmental conditions. It tends to occur earlier in northern sites and at high altitude, while it occurs later in southern sites at low altitude (Huchon and Démolin 1970). On the contrary, little is known about the drivers of yearly variation linked to temperatures in this species.

We here present an unprecedented dataset corresponding to a 15-year field monitoring experiment, documenting both individual dates of procession and dates of emergence in six sites located along an altitudinal gradient in southern France. We sampled 46479 caterpillars when they were leaving their host tree at the end of larval development. Each individual was placed in laboratory conditions at room temperature until moth emergence. The dataset does not provide information about the sex of the monitored individuals nor about mortality factors. This individual-based dataset brings original information and allows analyses that cannot be conducted with classical pheromone trapping data. Yet, note that 
the protocol used forced larvae to pupate in laboratory conditions and that the emergence data we provide cannot directly be compared to data from pheromone traps in the field.

\section{Sampling methods}

\section{Sampling description: Field sampling}

At each study site, 10 Austrian pine trees (Pinus nigra) were selected and fitted with a wire and a net strapped on the trunk down to the ground to trap the caterpillars leaving the tree in search of a pupation site and to prevent them from burying themselves. When PPM density was very low, nests were sampled on other trees in the vicinity and grafted to the selected pines. All the sites were visited every day from 1 January to 31 May each year. The caterpillars trapped at the base of each tree were thus sampled and counted every day. The larvae were then separated, placed individually in a glass tube and identified with a unique code. Sampling date and location were recorded for each individual. Caterpillars sampled from the same tree at the same date were identified as belonging to the same batch; note that they might originate from different nests of the same tree and thus belong to several families.

\section{Monitoring of adult emergence}

The sampled larvae were brought back every day to Malaucène (altitude $340 \mathrm{~m}$ a.s.I.) and left in a non-heated laboratory under natural photoperiods at room temperature (not recorded). As larvae do not feed at this stage, no pine needles were provided. A month after pupation, cocoons were taken from the tubes and were put into plastic boxes filled with untreated sawdust; individuals from the same batch were grouped in the same box, with 100 individuals maximum per box. The boxes were checked daily from 1 June to 30 September, to record emergences. In case all individuals did not emerge, the box was monitored again the following year to allow recording of the date of emergence of the diapausing pupae, until the fifth year.

\section{Geographic coverage}

Description: The experimental design took place along an altitudinal gradient in Mont Ventoux, France. The sampling sites are detailed in Table 1. The laboratory, where the larvae were allowed to pupate and were monitored daily, was situated in Malaucène (longitude 5.140, latitude 44.192 and altitude $340 \mathrm{~m}$ a.s.I.). The sites and the laboratory can be seen in Fig. 1.

\section{Taxonomic coverage}

Description: The study concerns the pine processionary moth Thaumetopoea pityocampa (Denis \& Schiffermüller) (Lepidoptera: Notodontidae) sampled from the black pine Pinus nigra (Arnold). 
Table 1.

Name, geographic coordinates and altitude of the study sites.

\begin{tabular}{|l|l|l|l|l|l|l|l|}
\hline Site name & Code & Country & State & Locality & Latitude (dd) & Longitude (dd) & Altitude \\
\hline Portail St Jean & G445 & France & Vaucluse & Malaucène & 44.164 & 5.141 & $445 \mathrm{~m}$ \\
\hline 2ème Plateforme & C671 & France & Vaucluse & Malaucène & 44.159 & 5.153 & $671 \mathrm{~m}$ \\
\hline Bramefam & B697 & France & Vaucluse & Malaucène & 44.162 & 5.158 & $697 \mathrm{~m}$ \\
\hline le Camp & A688 & France & Vaucluse & Malaucène & 44.164 & 5.155 & $688 \mathrm{~m}$ \\
\hline Fribouquet & F781 & France & Vaucluse & Beaumont-du-Ventoux & 44.168 & 5.177 & $781 \mathrm{~m}$ \\
\hline Les Ramayettes & R923 & France & Vaucluse & Beaumont-du-Ventoux & 44.169 & 5.196 & $923 \mathrm{~m}$ \\
\hline
\end{tabular}

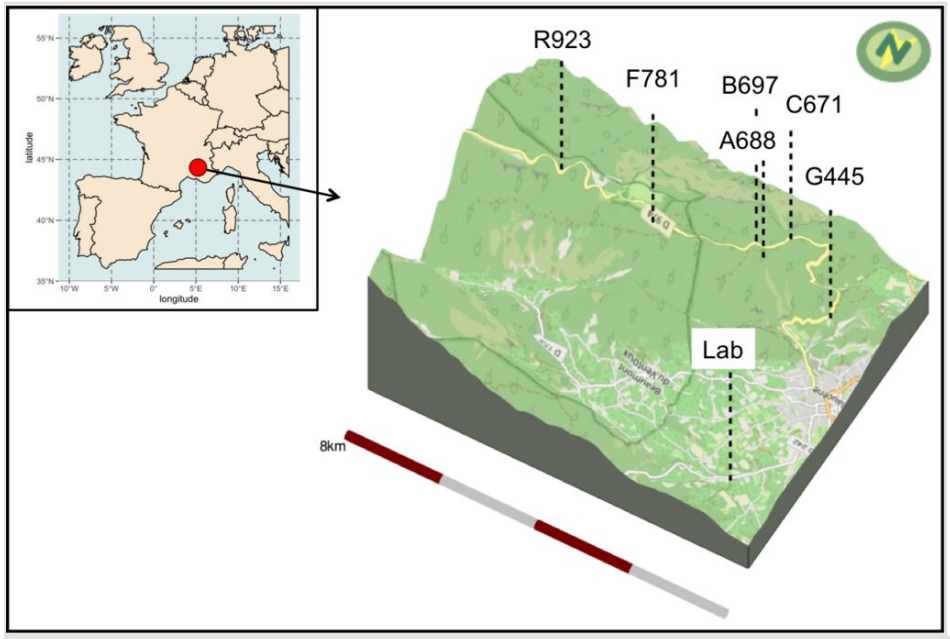

Figure 1. doi

$3 \mathrm{D}$ view of the six sites along the altitudinal gradient and location of the laboratory where the pupae were monitored until emergence. The map in the top left corner shows the location of the study site in France.

\section{Temporal coverage}

Notes: The study took place each year between 1970 and 1984. Caterpillars were sampled in the field every day between 1 January and 31 May and adult emergence was monitored between 1 June and 30 September.

\section{Usage licence}

Usage licence: Creative Commons Public Domain Waiver (CC-Zero) 


\section{Data resources}

Data package title: Identification, date of sampling and date of adult emergence in the six study sites

Resource link: https://data.inrae.fr/dataset.xhtml?persistentld=doi:10.15454/FGRKAY

\section{Number of data sets: 6}

Data set name: Emergence data for site G445 (file name: SiteG_EmergenceData.csv)

Data format: csv

\begin{tabular}{|l|l|}
\hline Column label & Column description \\
\hline site & Site code, refers to Table 1 \\
\hline year of sampling & Year when the caterpillars were sampled while in procession. Format yy \\
\hline batch & $\begin{array}{l}\text { Unique batch identifier (1 batch = one group of caterpillars sampled at the same time from } \\
\text { the same tree). The unique code is constructed as site-year-number }\end{array}$ \\
\hline date of sampling & $\begin{array}{l}\text { Day when the caterpillars from the batch identified in the previous column were sampled } \\
\text { and brought back to the lab. Format yyyy-mm-dd }\end{array}$ \\
\hline year of emergence & Year when adults emerged in the lab. Format yyyy \\
\hline date of emergence & $\begin{array}{l}\text { Day of the control of emergence (everyday between 1 June and } 30 \text { September each year } \\
\text { after sampling). Format yyyy-mm-dd }\end{array}$ \\
\hline number of individuals & Number of adults emerged at the corresponding date \\
\hline emerged & \\
\hline
\end{tabular}

Data set name: Emergence data for site C671 (file name: SiteC_EmergenceData.csv)

Data format: csv

\begin{tabular}{|l|l|}
\hline Column label & Column description \\
\hline site & Site code, refers to Table 1 \\
\hline year of sampling & Year when the caterpillars were sampled while in procession. Format yy \\
\hline batch & $\begin{array}{l}\text { Unique batch identifier (1 batch = one group of caterpillars sampled at the same time from } \\
\text { the same tree). The unique code is constructed as site-year-number }\end{array}$ \\
\hline date of sampling & $\begin{array}{l}\text { Day when the caterpillars from the batch identified in the previous column were sampled } \\
\text { and brought back to the lab. Format yyyy-mm-dd }\end{array}$ \\
\hline year of emergence & Year when adults emerged in the lab. Format yyyy \\
\hline date of emergence & $\begin{array}{l}\text { Day of the control of emergence (everyday between } 1 \text { June and } 30 \text { September each year } \\
\text { after sampling). Format yyyy-mm-dd }\end{array}$ \\
\hline
\end{tabular}


number of individuals Number of adults emerged at the corresponding date emerged

Data set name: Emergence data for site A688 (file name: SiteA_EmergenceData.csv)

Data format: csv

\begin{tabular}{|l|l|}
\hline Column label & Column description \\
\hline site & Site code, refers to Table 1 \\
\hline year of sampling & Year when the caterpillars were sampled while in procession. Format yy \\
\hline batch & $\begin{array}{l}\text { Unique batch identifier (1 batch = one group of caterpillars sampled at the same time from } \\
\text { the same tree). The unique code is constructed as site-year-number }\end{array}$ \\
\hline date of sampling & $\begin{array}{l}\text { Day when the caterpillars from the batch identified in the previous column were sampled } \\
\text { and brought back to the lab. Format yyyy-mm-dd }\end{array}$ \\
\hline year of emergence & Year when adults emerged in the lab. Format yyyy \\
\hline date of emergence & $\begin{array}{l}\text { Day of the control of emergence (everyday between 1 June and } 30 \text { September each year } \\
\text { after sampling). Format yyyy-mm-dd }\end{array}$ \\
\hline number of individuals & $\begin{array}{l}\text { Number of adults emerged at the corresponding date } \\
\text { emerged }\end{array}$ \\
\hline
\end{tabular}

Data set name: Emergence data for site B697 (file name: SiteB_EmergenceData.csv)

Data format: csv

\begin{tabular}{|l|l|}
\hline Column label & Column description \\
\hline site & Site code, refers to Table 1 \\
\hline year of sampling & Year when the caterpillars were sampled while in procession. Format yy \\
\hline batch & $\begin{array}{l}\text { Unique batch identifier (1 batch = one group of caterpillars sampled at the same time from } \\
\text { the same tree). The unique code is constructed as site-year-number }\end{array}$ \\
\hline date of sampling & $\begin{array}{l}\text { Day when the caterpillars from the batch identified in the previous column were sampled } \\
\text { and brought back to the lab. Format yyyy-mm-dd }\end{array}$ \\
\hline year of emergence & Year when adults emerged in the lab. Format yyyy \\
\hline date of emergence & $\begin{array}{l}\text { Day of the control of emergence (everyday between } 1 \text { June and } 30 \text { September each year } \\
\text { after sampling). Format yyyy-mm-dd }\end{array}$ \\
\hline number of individuals & Number of adults emerged at the corresponding date \\
\hline emerged & \\
\hline
\end{tabular}


Data set name: Emergence data for site F781 (file name: SiteF_EmergenceData.csv)

Data format: csv

\begin{tabular}{|l|l|}
\hline Column label & Column description \\
\hline site & Site code, refers to Table 1 \\
\hline year of sampling & Year when the caterpillars were sampled while in procession. Format yy \\
\hline batch & $\begin{array}{l}\text { Unique batch identifier (1 batch = one group of caterpillars sampled at the same time from } \\
\text { the same tree). The unique code is constructed as site-year-number }\end{array}$ \\
\hline date of sampling & $\begin{array}{l}\text { Day when the caterpillars from the batch identified in the previous column were sampled } \\
\text { and brought back to the lab. Format yyyy-mm-dd }\end{array}$ \\
\hline year of emergence & Year when adults emerged in the lab. Format yyyy \\
\hline date of emergence & $\begin{array}{l}\text { Day of the control of emergence (everyday between 1 June and } 30 \text { September each year } \\
\text { after sampling). Format yyyy-mm-dd }\end{array}$ \\
\hline $\begin{array}{l}\text { number of individuals } \\
\text { emerged }\end{array}$ & \begin{tabular}{l} 
Number of adults emerged at the corresponding date \\
\hline
\end{tabular} \\
\hline
\end{tabular}

Data set name: Emergence data for site R923 (file name: SiteR_EmergenceData.csv)

Data format: csv

\begin{tabular}{|l|l|}
\hline Column label & Column description \\
\hline site & Site code, refers to Table 1 \\
\hline year of sampling & Year when the caterpillars were sampled while in procession. Format yy \\
\hline batch & $\begin{array}{l}\text { Unique batch identifier (1 batch = one group of caterpillars sampled at the same time from } \\
\text { the same tree). The unique code is constructed as site-year-number }\end{array}$ \\
\hline date of sampling & $\begin{array}{l}\text { Day when the caterpillars from the batch identified in the previous column were sampled } \\
\text { and brought back to the lab. Format yyyy-mm-dd }\end{array}$ \\
\hline year of emergence & Year when adults emerged in the lab. Format yyyy \\
\hline date of emergence & $\begin{array}{l}\text { Day of the control of emergence (everyday between 1 June and } 30 \text { September each year } \\
\text { after sampling). Format yyyy-mm-dd }\end{array}$ \\
\hline number of individuals & Number of adults emerged at the corresponding date \\
\hline emerged & \\
\hline
\end{tabular}

\section{Additional information}

We provide graphics showing the dynamics of adult emergence for each site and year, showing both individuals emerging without prolonged diapause (univoltine cycle) and those 
emerging after one or more years of optional prolonged diapause (semi-voltine cycle) (Suppl. materials 1, 2, 3, 4, 5, 6).

We also provide a table and a graph documenting for each site and year the numbers and percentage of individuals directly emerging and individuals experiencing one year or more of prolonged pupal diapause (Suppl. materials 7,8 ).

\section{Acknowledgements}

This work was designed and developed by the late Dr Guy Démolin and his team of the INRA laboratory Unité de Recherches Forestières Méditerranéennes in Avignon and Station d'Ecologie du Mont-Ventoux, France. We are grateful to the numerous people from UEFM, Avignon, France, who helped to digitalise the data and made them available in numerical formats.

\section{References}

- $\quad$ Abarca M, Lill J (2019) Latitudinal variation in the phenological responses of eastern tent caterpillars and their egg parasitoids. Ecological Entomology 44 (1): 50-61.

https://doi.org/10.1111/een.12673

- $\quad$ Battisti A, Avcı M, Avtzis D, Ben Jamaa M, Berardi L, Berretima W, Branco M, Chakali G, El Alaoui El Fels MA, Frérot B, Hódar J, lonescu-Mălăncuş I, Ipekdal K, Larsson S, Manole T, Mendel Z, Meurisse N, Mirchev P, Nemer N, Paiva M, Pino J, Protasov A, Rahim N, Rousselet J, Santos H, Sauvard D, Schopf A, Simonato M, Yart A, Zamoum M (2015) Natural history of the processionary moths (Thaumetopoea spp.): new insights in relation to climate change. In: Roques A (Ed.) Processionary moths and climate change: an update. Springer / Quae Editions, 65 pp. https://doi.org/10.1007/978-94-

017-9340-7_2

- Huchon H, Démolin G (1970) La bioécologie de la processionnaire du pin. Dispersion potentielle - Dispersion actuelle. Revue Forestière Française 22: 220-234.

- Maurer JA, Shepard JH, Crabo LG, Hammond PC, Zack RS, Peterson MA (2018) Phenological responses of 215 moth species to interannual climate variation in the Pacific Northwest from 1895 through 2013. Plos One 13 (9): e0202850. https://doi.org/ $\underline{10.1371 / \text { journal.pone. } 0202850}$ 


\section{Supplementary materials}

\section{Suppl. material 1: Emergence curves for each cohort sampled in site G445 doi}

Authors: Martin J.-C., Rossi J.-P., Buradino M. \& Kerdelhué C.

Data type: Curves of daily adult emergence

Brief description: For each cohort (= individuals sampled the same year in the same site), the graph shows the dynamics of adult emergence. Dates of emergence are expressed as Julian days ( 1 January $=1$ and 31 December $=365$ or 366 ), so long-diapausing individuals are shown on the same graph in a different colour.

Download file $(37.89 \mathrm{~kb})$

\section{Suppl. material 2: Emergence curves for each cohort sampled in site $\mathbf{C 6 7 1}$ doi}

Authors: Martin J.-C., Rossi J.-P., Buradino M. \& Kerdelhué C.

Data type: Curves of daily adult emergence

Brief description: For each cohort (= individuals sampled the same year in the same site), the graph shows the dynamics of adult emergence. Dates of emergence are expressed as Julian days ( 1 January $=1$ and 31 December $=365$ or 366 ), so long-diapausing individuals are shown on the same graph in a different colour.

Download file $(33.47 \mathrm{~kb})$

\section{Suppl. material 3: Emergence curves for each cohort sampled in site A688 doi}

Authors: Martin J.-C., Rossi J.-P., Buradino M. \& Kerdelhué C.Martin J.-C., Rossi J.-P., Buradino M. \& Kerdelhué C.

Data type: Curves of daily adult emergence

Brief description: For each cohort (= individuals sampled the same year in the same site), the graph shows the dynamics of adult emergence. Dates of emergence are expressed as Julian days ( 1 January $=1$ and 31 December $=365$ or 366 ), so long-diapausing individuals are shown on the same graph in a different colour.

Download file $(36.08 \mathrm{~kb})$

\section{Suppl. material 4: Emergence curves for each cohort sampled in site B697 doi}

Authors: Martin J.-C., Rossi J.-P., Buradino M. \& Kerdelhué C.

Data type: Curves of daily adult emergence

Brief description: For each cohort (= individuals sampled the same year in the same site), the graph shows the dynamics of adult emergence. Dates of emergence are expressed as Julian days ( 1 January $=1$ and 31 December $=365$ or 366 ), so long-diapausing individuals are shown on the same graph in a different colour.

Download file $(35.38 \mathrm{~kb})$ 
Suppl. material 5: Emergence curves for each cohort sampled in site F781

Authors: Martin J.-C., Rossi J.-P., Buradino M. \& Kerdelhué C.

Data type: Curves of daily adult emergence

Brief description: For each cohort (= individuals sampled the same year in the same site), the graph shows the dynamics of adult emergence. Dates of emergence are expressed as Julian days ( 1 January $=1$ and 31 December $=365$ or 366 ), so long-diapausing individuals are shown on the same graph in a different colour.

Download file $(37.82 \mathrm{~kb})$

Suppl. material 6: Emergence curves for each cohort sampled in site R923 doi

Authors: Martin J.-C., Rossi J.-P., Buradino M. \& Kerdelhué C.

Data type: Curves of daily adult emergence

Brief description: For each cohort (= individuals sampled the same year in the same site), the graph shows the dynamics of adult emergence. Dates of emergence are expressed as Julian days ( 1 January $=1$ and 31 December $=365$ or 366 ), so long-diapausing individuals are shown on the same graph in a different colour.

Download file $(39.32 \mathrm{~kb})$

Suppl. material 7: Table showing the percentage of direct emergence and the percentage of individuals emerging after one or more years of prolonged diapause for each site and cohort doi

Authors: Martin J.-C., Rossi J.-P., Buradino M. \& Kerdelhué C.

Data type: Table (csv)

Brief description: For each site (G445, C671, A688, B697, F781, R923) and each sampling year, the Table shows how many individuals emerged directly (i.e. the same year) or after 1, 2, 3 or 4 years of prolonged diapause. The last column gives the corresponding percentages.

Download file $(9.96 \mathrm{~kb})$

Suppl. material 8: Curves showing the percentage of individuals having experienced a prolonged diapause for each site and year doi

Authors: Martin J.-C., Rossi J.-P., Buradino M. \& Kerdelhué C.

Data type: Graph

Download file $(142.67 \mathrm{~kb})$ 